\title{
0 relacionamento fisioterapeuta-paciente no método Pilates
}

\author{
The physiotherapist-patient relationship in the Pilates method
}

Marina Medici Loureiro Subti[ ${ }^{[0]}$, Mariane Lima de Souza $a^{[b]}$, Agnaldo Garcia ${ }^{[c]}$

\footnotetext{
${ }^{[a]}$ Mestre e doutoranda em Psicologia pela Universidade Federal do Espírito Santo (UFES), professora do curso de Música e de Fisioterapia da Universidade Federal do Espírito Santo (UFES), Vila Velha, ES - Brasil, e-mail: marina.fisio@hotmail.com

${ }^{[b]}$ Doutora em Psicologia pela Universidade Federal do Rio Grande do Sul (UFRGS), professora adjunta da Universidade Federal do Espírito Santo (UFES), Vila Velha, ES - Brasil.

${ }^{[c]}$ Doutor em Psicologia pela Universidade de São Paulo (USP), professor associado da Universidade Federal do Espírito Santo (UFES), Vila Velha, ES - Brasil.
}

Recebido: 07/01/2011 Received: 01/07/2011

Aprovado: 03/03/2011 Approved: 03/03/2011

\section{Resumo}

0 relacionamento entre terapeutas e pacientes tem sido foco de pesquisas em diversas profissões na saúde. No entanto, quando se refere à atuação da fisioterapia, o número de estudos ainda é reduzido, justificando a necessidade de maior aprofundamento sobre o assunto. O objetivo deste estudo foi conhecer e analisar as relações interpessoais estabelecidas entre fisioterapeuta e pacientes atendidos pelo método Pilates. Foram entrevistados dez pacientes de 31 a 73 anos, com diagnósticos clínicos variados, tempo de prática do Pilates entre três meses a quatro anos e com frequência semanal de duas a três vezes por semana. A coleta de dados deu-se por meio de entrevistas semiestruturadas as quais foram gravadas, transcritas e submetidas à análise qualitativa de conteúdo. 0 conteúdo das respostas foi organizado em cinco eixos temáticos: (a) as expectativas com o tratamento fisioterapêutico; (b) características de um bom tratamento; (c) a interrupção da prática do Pilates; (d) o que o Pilates representa na vida do paciente; e, (e) aspectos do relacionamento entre fisioterapeuta e paciente. Os dados sugerem que a tratamento fisioterapêutico permite a formação de um vínculo terapêutico específico entre os pacientes e o fisioterapeuta. Este relacionamento, incluindo a comunicação, foi considerado pelos pacientes um fator fundamental para o sucesso do tratamento e adesão ao tratamento.

Palavras-chave: Relações interpessoais. Papel do terapeuta. Tratamento.

\section{Abstract}

The relationship between therapists and patients has been the focus of research in various health professions; however, when referring to physical therapy, the number of studies is still low, justifying the need for further clarification on the matter. The objective of this study is to analyze the interpersonal relations established between therapist and patient in the Pilates method. Ten patients, from 31 to 73 years old, with different clinical diagnoses, have been interviewed. All have used Pilates from three months to four years, two to three times a week. Semi-structured interviews have been employed, which were recorded, transcribed and analyzed qualitatively. The content has been organized into five themes: (a) expectations about Physiotherapy treatment; (b) characteristics of a good treatment; (c) the discontinuation of the practice of Pilates; (d) what Pilates method represents in the patient's life; (e) aspects of the relationship between therapist and patient. Content analysis data suggest that there is a therapeutic relationship between patients and 


\begin{abstract}
therapists; this relationship, including communication, professional knowledge and a satisfying relationship between those involved in this process were considered fundamental factors for successful treatment by patients.
\end{abstract}

Keywords: Interpersonal relationship. Therapist role. Treatment.

\section{Introducão}

O campo de atuação da Fisioterapia vem crescendo significativamente nos últimos anos em nosso país, atendendo pacientes com os mais variados diagnósticos e disfunções. Sendo uma profissão relativamente recente, de nível superior a partir de 1969, pesquisas na área são necessárias para sua consolidação e fundamentação da prática do fisioterapeuta.

Quando se trata do relacionamento interpessoal entre terapeuta e paciente, a maioria dos trabalhos publicados sobre o tema tem origem na Medicina, Enfermagem ou Psicologia. Raros são os estudos sobre a percepção dos pacientes em relação ao atendimento fisioterapêutico ou sobre o vínculo estabelecido com o profissional que o atende, considerando suas queixas, suas expectativas e sua impressão sobre o atendimento e a relação paciente-fisioterapeuta.

Apesar de a prática fisioterápica permitir um contato próximo e frequente entre fisioterapeuta e paciente, gerando possibilidades de relacionamento interpessoal típicas dessa área profissional, ainda há poucas pesquisas sobre a natureza desse relacionamento no Brasil. Face à diversidade da prática profissional na área de Fisioterapia, o presente trabalho buscou investigar o relacionamento entre fisioterapeuta e paciente em uma atividade específica empregada, o método Pilates.

\section{0 método Pilates}

Durante a Primeira Guerra Mundial, um alemão chamado Joseph H. Pilates (1880-1967) desenvolveu, com base em observações, uma série de exercícios que poderiam curar lesões e problemas relacionados à postura. 0 método trazia excelentes resultados na época e, com o passar do tempo, foi levado ao conhecimento dos norte-americanos, para, em seguida, alcançar o mundo a partir de seus difusores (Craig, 2005). Apesar de ter sido designado de Contrologia por seu criador, graças aos princípios básicos da técnica que mistura controle mental, controle corporal, respiração e atividade física, o método acabou sendo conhecido pelo nome de Pilates em homenagem a seu criador (Pilates \& Miller, 1998; Ungaro, 2002).

0 método Pilates representa, portanto, um programa de condicionamento físico e mental ligado a uma vasta quantidade de exercícios potenciais que utilizam pequenos movimentos terapêuticos desenvolvidos para contribuir na cura de lesões. Os exercícios podem ser praticados em modalidades como solo, bola e em aparelhos desenvolvidos especialmente para a realização do método. Além disso, o Pilates ainda traz como benefícios a melhoria da concentração, coordenação motora e consciência corporal (Kolyniak, 2004). Neste artigo, o termo "Pilates" será utilizado para denominar a técnica.

\section{Relacionamento interpessoal entre fisioterapeuta e paciente}

Os serviços de saúde oferecidos à sociedade geralmente são mediados por relacionamentos entre profissionais que prestam o serviço e os pacientes que os recebem. As pesquisas sobre essa forma de relacionamento, contudo, tem contemplado mais o relacionamento interpessoal entre médico e paciente, com ênfase nas questões ligadas ao processo de comunicação estabelecido entre essas partes (Garcia, 2005). No diagnóstico dado pelo médico e a terapêutica administrada, a familiaridade, a confiança e a colaboração estão implicadas nos resultados satisfatórios (Gadamer, 1994). A proposta de conhecer melhor os aspectos envolvidos no adoecimento do paciente é responsável pela efetiva promoção da saúde, ao considerar o enfermo em sua integridade física, psíquica e social e não somente de um ponto de vista biológico (Wulff et al., 1995). 
O papel do escutar é destacado por Marinho (1995) como importante na relação terapêutica estabelecida. Conforme Perestrello (1989, p. 96):

Para ser terapeuta, precisará ao menos ter apreço pelo paciente e para isso é preciso algo mais do que lhe fazer perguntas, examiná-lo... É preciso respeitar a sua individualidade, sua pessoa, começando por ouvir o que a pessoa tem a dizer.

Caldeira (2001) enfatiza a importância da criação de um espaço na relação onde o paciente tem a permissão de expressar-se e ambos participam efetivamente do processo de cura. Neste caso, o paciente se sente aceito, compreendido, amado e sem culpa, criando experiências de grande importância para ele. Um dos fatores necessários para que a fisioterapia atue diretamente no desenvolvimento do paciente está na maneira como o paciente se relaciona com o fisioterapeuta e vice-versa.

A partir da prática profissional, pode-se observar que, à medida que os pacientes se envolvem no tratamento fisioterapêutico, relações interpessoais marcadas pela afetividade se desenvolvem, as quais podem afetar o curso e a qualidade do tratamento em questão. No caso da Fisioterapia, esse relacionamento é fundamental, uma vez que o tratamento pode se estender por anos, com um contato frequente, até várias vezes por semana e com uma proximidade expressiva, graças à natureza do atendimento, incluindo o próprio contato físico. A reciprocidade também favorece as aquisições de habilidades interativas, bem como a evolução de um conceito de interdependência (Ribeiro, Moraes \& Beltrame, 2008). Segundo Copetti (2001), a reciprocidade pode gerar uma motivação capaz de levar os indivíduos prosseguirem e acelerarem suas atividades, melhorando o padrão de aprendizagem.

Os profissionais de saúde que se propõem a tratar o paciente precisam buscar o sentido e o significado da queixa que o cerca. A leitura parcial desse paciente representa, de certa forma, a fragilização da relação terapêutica (Loyola, 1984) quando desconsidera que a eficácia terapêutica depende de todos os atos que envolvem o encontro entre o paciente e o profissional (Ferreira, 1993).

Nesse contexto, a fisioterapia apresenta-se como uma profissão da área de saúde que lida com disfunções do movimento humano e sua prevenção. Como ferramentas de trabalho, utiliza técnicas e procedimentos variados para dar conta de seus objetivos terapêuticos. Nesse panorama, o desenvolvimento de relacionamento entre fisioterapeuta e paciente apresenta-se como algo natural e muito provável de acontecer entre essas partes, visto que o tratamento em questão apresenta fatores favoráveis ao surgimento de um relacionamento interpessoal, tais como longo período de convivência, estímulos táteis prolongados e comunicação em boa parte do atendimento fisioterapêutico.

Durante as sessões de fisioterapia, é necessário que o paciente não apenas observe e execute as atividades propostas pelo fisioterapeuta, mas que esse (paciente) se reconheça como ativo e chave fundamental no processo terapêutico. Afinal, a efetividade do tratamento encontra-se numa via de mão dupla, em que os pacientes precisam ser participantes ativos sob a orientação do fisioterapeuta. A tendência é que, à medida que os participantes se envolvam em relações interpessoais, características como afetividade, reciprocidade e confiança, respeito e vínculo se desenvolvam e se tornem mais evidentes. Considerando todos os aspectos presentes na relação que se estabelece entre fisioterapeuta e paciente, ouvir e analisar o que pacientes consideram a respeito do tratamento que recebem, e o estabelecimento do vínculo entre eles constitui o foco central deste artigo. Portanto, este estudo objetiva conhecer e analisar as relações interpessoais estabelecidas entre fisioterapeuta e pacientes atendidos pelo método Pilates. 0 conhecimento dessas relações permitirá entender como se processa o vínculo estabelecido entre paciente e fisioterapeuta, verificando o grau de importância desse vínculo no tratamento e para a vida dos pacientes estudados.

\section{Método}

\section{Participantes}

Participaram da pesquisa dez pacientes voluntários, com idades variando de 31 a 73 anos, atendidos pelo método Pilates, no município de Vila Velha, ES, apresentando diagnósticos clínicos variados. 0 tempo de prática do Pilates foi de três meses a quatro anos, com frequência de duas a três vezes por semana. 0 número de participantes foi definido seguindo o critério de saturação teórica da amostra (Patton, 1980). 
Instrumentos

Após a leitura do termo de consentimento livre e esclarecido a explicação da pesquisa, os indivíduos que desejassem participar assinavam o termo em duas vias. Em seguida, os pacientes foram entrevistados sobre a percepção da relação estabelecida entre eles e os fisioterapeutas que os atende. As questões englobaram dados como gênero, idade, tempo e frequência da prática do Pilates e questionamentos ligados à percepção quanto ao tratamento, o relacionamento estabelecido entre fisioterapeuta e paciente, as dimensões do relacionamento e a representação do Pilates na vida dos participantes.

\section{Procedimento de análise dos dados}

As entrevistas foram gravadas, transcritas na íntegra, seu conteúdo foi analisado (Bardin, 1977) e organizado em temas ou categorias recorrentes e relevantes identificados nas falas dos participantes.

\section{Princípios éticos}

0 trabalho foi aprovado pelo comitê de ética em pesquisa do Hospital Infantil Nossa Senhora da Glória, seguindo as diretrizes do Conselho Nacional de Saúde. 0 anonimato de todos os participantes foi preservado e suas entrevistas foram descartadas após a análise dos dados.

\section{Resultados}

A entrevista com os dez participantes revelou homogeneidade nas falas. Os motivos levantados pelos participantes para a realização do Pilates foram diversos, desde causas como lombalgia, osteoporose, artrose, dores no joelho, busca por melhora do componente físico e psicológico e por questões pessoais, conforme apresentado no Quadro 1.

0 conteúdo das entrevistas foi organizado em cinco categorias previamente estabelecidas:

Quadro 1 - Participantes: gênero, idade e envolvimento com o Pilates

\begin{tabular}{|c|c|c|c|}
\hline Participantes & $\begin{array}{l}\text { Gênero e } \\
\text { idade }\end{array}$ & $\begin{array}{l}\text { Tempo de Pilates } \\
\text { e frequência semanal }\end{array}$ & Motivos para realização do Pilates \\
\hline P1 & $\begin{array}{l}\text { Feminino } \\
73 \text { anos }\end{array}$ & $\begin{array}{l}\text { F: } 2 \text { vezes por semana } \\
\text { T: } 3 \text { meses }\end{array}$ & $\begin{array}{l}\text { Lombalgia } \\
\text { Orteosporose } \\
\text { Artrose }\end{array}$ \\
\hline P2 & $\begin{array}{l}\text { Feminino } \\
65 \text { anos }\end{array}$ & $\begin{array}{l}\text { F: } 2 \text { sessões } \\
\text { T: } 6 \text { meses }\end{array}$ & $\begin{array}{l}\text { Indicação de outras pessoas. } \\
\text { Melhorar o condicionamento físico. }\end{array}$ \\
\hline P3 & $\begin{array}{l}\text { Masculino } \\
72 \text { anos }\end{array}$ & $\begin{array}{l}\text { F: } 2 \text { vezes por semana } \\
\text { T: } 4 \text { meses }\end{array}$ & $\begin{array}{l}\text { Ociosidade por causa da idade. } \\
\text { Ter uma ocupação diária. }\end{array}$ \\
\hline P4 & $\begin{array}{l}\text { Feminino } 62 \\
\text { anos }\end{array}$ & $\begin{array}{l}\text { F: } 2 \text { vezes por semana } \\
\text { T: } 10 \text { meses }\end{array}$ & $\begin{array}{l}\text { Indicação médica. } \\
\text { Cirurgia na coluna. }\end{array}$ \\
\hline P5 & $\begin{array}{l}\text { Masculino } \\
31 \text { anos }\end{array}$ & $\begin{array}{l}\text { F: } 3 \text { vezes por semana } \\
\text { T: } 4 \text { meses }\end{array}$ & Instrução médica. Dor no joelho. \\
\hline P6 & $\begin{array}{l}\text { Feminino } \\
38 \text { anos }\end{array}$ & $\begin{array}{l}\text { F: } 2 \text { vezes por semana } \\
\mathrm{T}: 1 \text { ano }\end{array}$ & $\begin{array}{l}\text { Trabalho individualizado no Pilates, treino de força e alongamento. } \\
\text { Dispende menos tempo por semana. }\end{array}$ \\
\hline P7 & $\begin{array}{l}\text { Masculino } \\
64 \text { anos }\end{array}$ & $\begin{array}{l}\text { F: } 2 \text { vezes por semana } \\
\mathrm{T}: 4 \text { anos }\end{array}$ & Falecimento da esposa e influência do filho. \\
\hline P8 & $\begin{array}{l}\text { Feminino } \\
50 \text { anos }\end{array}$ & $\begin{array}{l}\text { F: } 2 \text { vezes por semana } \\
\text { T: } 2 \text { anos }\end{array}$ & $\begin{array}{l}\text { Problemas com as colunas cervical e lombar; indicação de um } \\
\text { fisioterapeuta e de um cliente. }\end{array}$ \\
\hline P9 & $\begin{array}{l}\text { Feminino } \\
43 \text { anos }\end{array}$ & $\begin{array}{l}\text { F: } 2 \text { vezes por semana } \\
\text { T: } 2,5 \text { anos }\end{array}$ & Indicação médica por problema na coluna (hérnia de disco). \\
\hline P10 & $\begin{array}{l}\text { Feminino } \\
50 \text { anos }\end{array}$ & $\begin{array}{l}\text { F: } 2 \text { vezes por semana } \\
\mathrm{T}: 2 \text { anos }\end{array}$ & Indicação médica por ter hérnia de disco lombar. \\
\hline
\end{tabular}

Fonte: Dados da pesquisa. 
a) expectativas em relação à Fisioterapia;

b) características de um bom tratamento;

c) interrupção da prática da Fisioterapia e seus significados;

d) que a Fisioterapia representa na vida do paciente;

e) relação entre fisioterapeuta e paciente no método Pilates. Esta última categoria foi subdividida em três subcategorias:

a) descrição do relacionamento;

b) conteúdo das conversas;

c) vínculo entre paciente e fisioterapeuta.

\section{Expectativas em relação à Fisioterapia}

As expectativas associadas à Fisioterapia podem ser classificadas em dois grupos: as expectativas relacionadas ao bem-estar físico e aquelas ligadas a fatores sociais. Em relação ao bem-estar físico, as expectativas vão desde o desejo de redução e supressão de dores e recuperação de movimentos até melhorar o condicionamento e a resistência física, a postura, a força muscular e emagrecer, aumentando a disposição para fazer as atividades de vida diária com implicações para a qualidade de vida. Ao lado do bem-estar físico, ainda foi citada a busca por socialização. Algumas frases dos participantes podem ilustrar as expectativas indicadas. 0 desejo de redução e supressão de dores foi apontado: "eu queria parar de sentir aquele desconforto na coluna, porque ninguém gosta de sentir dor, eu queria afastar a ideia de ter que ficar dependente de remédios. Enquanto eu faço Pilates, eu me sinto bem e sem crises de dor" (PF8). Além da dor, um melhor condicionamento físico também foi buscado: "eu estava com sobrepeso, falta de resistência, dores no joelho, isso tudo me atrapalhava realizar as atividades profissionais e as demais, com o Pilates eu emagreci, reduzi as dores do joelho, melhorei a definição muscular e consigo relaxar" (PF6). Uma melhor condição física foi indicada como melhoria de qualidade de vida: "eu queria melhorar a minha qualidade de vida, não ter que enfrentar aquelas crises que já estavam sendo muito pesadas pra mim, e eu tenho conseguido isso com o Pilates" (PF10). Finalmente, os aspectos sociais também foram lembrados:

"eu busquei um pouco mais de socialização, entrar em contato com os outros, eu estava muito fechado desde a morte de minha esposa. Eu achei que o Pilates é uma coisa que me traz prazer, eu estou mais feliz, meu humor melhorou, minha postura, minha vida" (PM7).

Nota-se, assim, a busca tanto de reabilitação física quanto a satisfação de anseios emocionais e afetivos por meio de novas relações sociais. Apesar de o foco da presente investigação voltar-se para o relacionamento entre fisioterapeuta e paciente, a possibilidade de o tratamento fisioterapêutico permitir novas relações interpessoais também merece mais investigações.

Para os participantes da pesquisa, o sucesso do tratamento teve vários motivos, incluindo a disciplina em realizar os exercícios estipulados, a regularidade na realização do tratamento, a vontade de melhorar o estado de saúde, a empatia com o profissional, a confiança depositada no fisioterapeuta e na técnica escolhida e a afinidade com o fisioterapeuta em questão.

\section{As características de um bom tratamento}

Um segundo ponto investigado foram as características de um bom tratamento, na visão dos pacientes. As respostas podem ser classificadas em duas categorias: o papel do fisioterapeuta e o papel do paciente. Em ambos os casos, contudo, os pacientes se referem à relação entre ambos. 0 fisioterapeuta deve ser atencioso e tratar cada paciente com suas especificidades, de modo profissional. Um paciente destaca que o tratamento fisioterapêutico deve ser o mais profissional possível e que o fisioterapeuta deve conhecer os limites entre a relação profissional e a amizade: "o profissional não deve se deixar influenciar pela amizade, e sim a questão profissional deve vir em primeiro lugar sempre para que o tratamento seja bom" (PM3). Outra fala exemplifica a posição do paciente como responsável pelo sucesso do tratamento, assim como o envolvimento do fisioterapeuta e sua responsabilidade para que os resultados com a fisioterapia sejam satisfatórios:

"eu acho que um bom tratamento fisioterapêutico envolve feedback do paciente, é preciso também que o fisioterapeuta conheça as potencialidades e os limites do seu paciente, cada paciente é um indivíduo diferente, então essa percepção e esse cuidado é que devem vir em primeiro lugar para o tratamento dar certo. No Pilates eu me sinto única, respeitada, recebo um olhar mais atento, pra mim isso é qualidade na Fisioterapia" (PF9). 
Em suma, o bom tratamento implica diretamente em um relacionamento interpessoal marcado pela atenção e pela singularidade do paciente. Um bom relacionamento é apontado como uma condição necessária para o conhecimento técnico-profissional possa ser aplicado de modo eficiente.

\section{A interrupção da prática da Fisioterapia}

A interrupção é vista como uma perda tanto no aspecto de saúde física quanto no aspecto relacional. Os participantes apontaram que sentiriam falta da relação estabelecida com o fisioterapeuta e dos exercícios propostos pela técnica. Nota-se, na fala se alguns, a formação de apego tanto com o fisioterapeuta quanto com o Pilates. Alguns chegam a afirmar que não desejam melhorar completamente de suas dores, senão teriam que deixar de ir à Fisioterapia e perderiam o contato com seu fisioterapeuta: "vou sentir falta da melhora de qualidade de vida que eu alcancei com os exercícios, além do meu fisioterapeuta, eu tenho muito carinho por ele" (PF2). Ainda, "olha, eu sentiria falta desse contato porque já criou-se uma amizade, sentiria também a falta do tratamento em si, não quero mais voltar a sentir as velhas dores de coluna" (PF1). Uma vez mais,

"sentiria falta da profissional, mais ainda do que do Pilates, eu fui recebida com muito carinho, ela me dá atenção, isso não tem preço. Claro que não deixo de falar do tratamento, ele é muito bom, as duas coisas acabam de misturando eu acho" (PF4).

Diante da possibilidade de interrupção do tratamento, pode-se perceber a importância do caráter relacional entre paciente e fisioterapeuta, além da questão da saúde física.

\section{0 papel da Fisioterapia na vida do paciente}

A partir dos relatos dos pacientes, a Fisioterapia (no caso, especificamente o método Pilates) foi comparado a um hábito, como algo a ser praticado para o resto da vida, pois representa uma melhoria de qualidade de vida, redução e eliminação dos sintomas das doenças e melhora do componente físico e mental: "o Pilates tem representado essa energia que eu estou tendo, a disposição, a vontade de lutar contra essas dores, eu acho que a minha relação com o Pilates vai ser eterna!" (PF10). Em outro caso, "o Pilates tem uma importância fenomenal, faz parte da minha vida, eu me sinto bem"(PM5). E ainda, "o Pilates hoje é uma peça fundamental eu diria, é como tomar banho todos os dias, me alimentar, é um compromisso comigo mesma e com a minha saúde física e mental" (PF6).

\section{Aspectos do relacionamento entre fisioterapeuta e paciente}

0 relacionamento entre fisioterapeuta e paciente apresenta algumas particularidades ligadas à prática profissional. A frequência e duração do contato podem ser consideradas expressivas, de cerca de duas a três horas semanais, misturando comunicação oral e contato físico, criando circunstâncias para o surgimento de um relacionamento interpessoal com características específicas. Três aspectos foram observados:

a) a descrição do relacionamento;

b) o conteúdo das conversas;

c) o vínculo entre paciente e fisioterapeuta.

\section{A descrição do relacionamento}

Ao descreverem o relacionamento, alguns aspectos se destacam. Primeiramente, o fisioterapeuta é identificado como protagonista e responsável pela relação. Os pacientes falam pouco sobre seus papéis na construção desse relacionamento. Algumas falas ilustram esse comportamento por parte dos pacientes "a relação é muito tranquila, a forma como ele administra o Pilates e como ele é sempre brincalhão, conversa muito, é atencioso (PM3) e meu professor me orienta bem, se foca no que eu preciso, o diálogo é muito importante nessa relação, ele é amigo, tem carinho, é um laço paternal" (PM7).

Na percepção dos pacientes, a relação com o fisioterapeuta é definida como uma relação de amizade com características peculiares, diferente das relações com amigos próximos ou familiares. Dois pacientes descrevem a relação como uma amizade, destacando, contudo, o lado profissional: "é uma relação de amizade, respeito, ética, existe brincadeira, mas dentro do limite profissional" (PF4) e "é uma relação de amizade mas botando o lado profissional na frente" (PM5). Uma das falas descreve a natureza ambígua da relação entre fisioterapeuta e paciente, como uma amizade e um relacionamento profissional: 
"é um tipo de amizade que a gente não sabe em qual categoria vai encaixar, mas assim, não deixa de ser amizade e não deixa de ter a importância na vida da gente, o relacionamento entre fisioterapeuta e paciente é fundamental para o sucesso do tratamento, não adianta só uma técnica boa, o relacionamento é tão importante quanto" (PF6).

A relação ainda é descrita como agradável, satisfatória, empática, tranquila e de confiança.

\section{0 conteúdo das conversas}

Os assuntos das conversas nos intervalos dos exercícios são variados, incluindo questões do dia a dia ligadas ao trabalho, ao estudo, aos problemas de saúde que os fizeram buscar a prática do Pilates, entre outros. Apesar de a conversa com o fisioterapeuta ser considerada importante, não são abordados assuntos íntimos ou questões pessoais: "nós falamos sobre futebol, eu torço bem para o Flamengo e ele teima em torcer para o Fluminense, fazer o que né?" (PM5). Ainda:

"a gente conversa sobre as coisas do dia a dia, sobre o dia de trabalho estressante, sobre filmes, viagens, comida, mas as coisas íntimas não, as coisas pessoais não são compartilhadas, e acho que nem seria o momento para isso, trata-se de uma relação que mistura amizade mas ao mesmo tempo muito profissionalismo" (PF8).

Dois pontos se destacam em relação ao conteúdo das conversas: a diversidade de temas e a intimidade restrita.

\section{0 vínculo entre paciente e fisioterapeuta}

Vínculo, neste estudo, é considerado um tipo de relacionamento marcado pelo compromisso, ou pela intenção de manter esse relacionamento. A ideia de vínculo já havia aparecido em outros trechos da entrevista. Dois participantes consideraram o vínculo como algo profissional, com o intuito de alcançar fins terapêuticos. Um deles ressaltou a importância de considerar tal relacionamento como profissional, mesmo que exista contato físico e muita troca de informações verbais.

Para outra participante, o vínculo é formado por meio de uma carência de quem procura o atendimento a partir dessa técnica de tratamento. No instante em que o paciente recebe um bom atendimento, com atenção e carinho por parte do fisioterapeuta, a formação do vínculo é facilitada. Ela diz que

"esse atendimento mais próximo, associado com a carência que a gente traz, facilita a criação desse vínculo, acho que é até uma dependência, e se como é neste caso você sente que tem reciprocidade, aí esse vínculo tende a se perpetuar" (PF1).

Alguns relatos indicaram a importância do fisioterapeuta perceber as nuances do seu paciente:

"o fisioterapeuta tem que te enxergar mais a fundo, te ver como alguém mais complexo, como um ser repleto de medos e angústias, minha postura ruim ou meus outros problemas podem ser resultado de coisas emocionais, então, o fisioterapeuta deve perceber isso" (PF9).

Outro:

"a formação do vínculo vai depender de como o fisioterapeuta conversa com a gente, como ele se preocupa, daí vem a simpatia, a afinidade, e isso pode vir a ser amizade, porque não?" (PM7)

E ainda:

"no tratamento, tanto o toque como as palavras são importantes, isso serve para qualquer profissão da saúde. Aquele que procura um fisioterapeuta precisa dele, tem uma carência ali, uma dor, a atenção é fundamental na formação desse vínculo" (PF6).

Na percepção deste último, a formação do vínculo entre fisioterapeuta e paciente é fundamental para o sucesso do tratamento. Como já observado anteriormente, há uma ambiguidade entre as características profissionais e pessoais do relacionamento. Por outro lado, as respostas novamente apontam para o relacionamento como uma dimensão central para o trabalho do fisioterapeuta.

As falas dos pacientes revelam o grau de importância que atribuem à relação construída com o profissional que os atende. Alguns apontam como uma relação de amizade, outros como uma relação profissional que envolve carinho, confiança e respeito. Os exercícios são colocados como parte indispensável no sucesso do tratamento. É possível perceber que existe apego ao relacionamento interpessoal que se estabelece e ao tratamento proposto. 


\section{Discussão}

Conhecer a perspectiva dos pacientes quanto ao relacionamento pode contribuir não apenas para a prática profissional do fisioterapeuta mas também com o conhecimento sobre o relacionamento interpessoal de forma mais ampla.

Quanto às expectativas em relação à Fisioterapia, os participantes consideraram que foram alcançadas de forma satisfatória, demonstrando a eficácia do tratamento para cada tipo de disfunção apresentada. Isto é um fato importante, pois adoecer oferece a sensação de desamparo ao indivíduo, ameaçando a sua posição de cidadão, já que as consequências do adoecimento podem prejudicar sua atividade produtiva, com consequências refletidas na sua vida pessoal, familiar e social (Moreira, Nogueira \& Rocha, 2007). Possivelmente, as razões para o sucesso da Fisioterapia, particularmente do método Pilates, decorrem do fato de que a técnica funciona em sincronia com corpo e mente (Selby \& Herdman, 2000).

Dentro dessa concepção de atendimento individualizado e direcionado à disfunção de cada paciente, o método proporciona efeitos benéficos para variados tipos de doenças (Pilates \& Miller, 1998). Em termos de tratamento fisioterapêutico, a importância do relacionamento entre profissional e paciente é afirmada em vários trechos da entrevista. 0 estabelecimento das relações com os pacientes permite a melhora dos resultados terapêuticos e a adesão ao tratamento, aumentando o grau de satisfação do paciente (Camprara \& Rodrigues, 2004). Segundo Marinho e Fiorelli (2005), o sucesso terapêutico na Fisioterapia depende de fatores ligados ao paciente e ao fisioterapeuta. 0 paciente deve ter consciência do processo de adoecimento, conhecendo suas limitações e os possíveis caminhos para alcançar a melhora e o fisioterapeuta precisa ver esse paciente como um ser complexo, que carrega medos, expectativas, vontades, dúvidas, carências e desejo de ser curado e entendido em sua plenitude.

0 presente estudo apontou dois fatores primordiais no atendimento em Fisioterapia, particularmente empregando o método Pilates. De um lado, está o conhecimento e uso correto da técnica. Por outro lado, a relação interpessoal paciente-fisioterapeuta é reconhecida como fator integrante e essencial ao tratamento. Os resultados encontrados aproximam-se dos encontrados por Moreira, Nogueira e Rocha (2007), quanto ao processo de adoecimento de pacientes que buscam o serviço de Fisioterapia. Para eles, quando se busca o tratamento fisioterapêutico, espera-se o suporte profissional. 0 pedido de ajuda a esse profissional pode vir como forma de partilhar a confusão, aliviar medos, livrar-se do desconforto e do desconhecido, receber esperanças de melhoria na condição de saúde.

Esta pesquisa aponta para uma relação específica que se estabelece entre fisioterapeuta e paciente. A relação, aparentemente, compartilha propriedades tipicamente de uma relação de amizade e profissional. Uma diferença importante entre esse relacionamento e uma amizade típica, por exemplo, está no índice mais baixo de intimidade.

A relação estabelecida entre fisioterapeuta e paciente é complexa, envolvendo aspectos que se aproximam de uma relação de amizade, mantendo-se, contudo, como um relacionamento exclusivamente profissional. Essa proximidade entre fisioterapeuta e paciente também é considerada como um fator de sucesso no tratamento. A dificuldade para o profissional, nesse sentido, é reconhecer os limites entre um relacionamento profissional de caráter amistoso e uma amizade. Neste contexto, a confiança deve estar presente em todo o processo de reabilitação e relação terapêutica, já que são depositadas expectativas de cura nos profissionais de saúde (Moreira, Nogueira \& Rocha, 2007). A maior proximidade entre profissional e paciente, possivelmente está relacionada à natureza do tratamento fisioterapêutico. Durante uma sessão de Fisioterapia escutam-se queixas, recomendações, orientações e prescrições. Há proximidade física, de modo que corpos ou partes do corpo são tocadas, pressionadas ou massageadas (Moreira, Nogueira \& Rocha, 2007).

Nessa troca de estímulos táteis e verbais, os pacientes deste estudo interagiram com o fisioterapeuta, identificando a importância de conversas e da comunicação para garantir parte do sucesso terapêutico.

Segundo Silva (1996), a tarefa do profissional da saúde é decodificar, decifrar e perceber o significado da mensagem que o paciente envia para, só então, estabelecer um plano de cuidados adequado e coerente com as suas percepções e necessidades. Ressalta, ainda, que o profissional por interagir diretamente com o paciente, precisa estar mais atento ao uso adequado das técnicas de comunicação interpessoal. Concordamos com os achados de Silva (1996), pois acreditamos que, ao fazer o uso correto da comunicação, o fisioterapeuta estará se 
capacitando para perceber o paciente como pessoa que pensa, sente e está inserida num contexto e não apenas como objeto de seu cuidar. Especificamente no presente caso, os pacientes veem o tratamento fisioterapêutico como algo que ultrapassa a mera aplicação de técnicas profissionais. Esperam e avaliam de forma positiva um maior envolvimento pessoal e diferenciado com o fisioterapeuta, a ponto de considerarem tal relacionamento como algo próximo a uma amizade, ainda que um certo distanciamento seja valorizado, por se tratar de uma relação profissional.

0 relacionamento interpessoal entre fisioterapeuta e paciente, graças ao contato prolongado, favorece o estabelecimento de um vínculo terapêutico. Ao utilizar-se apropriadamente da comunicação, aliada a esse vínculo terapêutico, o profissional tem ampliada sua capacidade de observação, podendo detectar expressões verbais e não verbais indicativas de situações relevantes, sobre as quais poderá interagir ou não, que passariam despercebidas por outros profissionais.

Para a criação de um vínculo, é preciso estar atento à comunicação verbal e corporal (Silva, 1996). Marinho e Fiorelli (2005) consideram que o espaço e a relação terapêutica devem oferecer condições para que o profissional de saúde e o paciente expressem suas emoções, veiculando informações verbais e corporais, criando um ambiente provido de aconchego e afeto. Existem sinais evidentes e reconhecidos como característicos do processo de dor, manifestados sob a forma de vários comportamentos, dentre eles choro, gemidos, expressão facial de sofrimento, postura corporal encurvada, reveladas durante o processo de reabilitação e tratamento (Lobato, 1992). A eficácia terapêutica depende de todos os atos que envolvem o encontro entre o paciente e o profissional (Ferreira, 1994). A presente pesquisa revelou que quanto mais satisfeito estão os pacientes, sendo suas expectativas com o tratamento alcançadas, maior será a manifestação de afeto e carinho pelo fisioterapeuta, assim como o desejo de continuar a relação e o tratamento.

\section{Considerações finais}

O presente estudo indicou a importância atribuída ao relacionamento interpessoal entre paciente e fisioterapeuta no tratamento ao lado da técnica em questão. 0 relacionamento e vínculo que se estabelece são considerados fatores de sucesso para o tratamento. Entender quais são as expectativas, as vontades e as limitações dos pacientes que procuram o serviço de fisioterapia pelo método Pilates é garantir que o uso de uma comunicação adequada seja eficaz no sucesso do tratamento. 0 relacionamento entre fisioterapeuta e paciente neste estudo revelou-se como uma forma de relação peculiar, que se mostra entre a amizade e o relacionamento profissional, tendo características que passam por ambas, mas que não a define isoladamente. Sendo assim, é preciso conhecer mais sobre este tema entre fisioterapeutas e pacientes nas diversas áreas de atuação da profissão a fim de entender cada vez mais sobre as peculiaridades dessa relação.

\section{Agradecimentos}

À Fundação de Apoio à Pesquisa, do Espírito Santo, pelo incentivo à pesquisa no nosso Estado.

\section{Referências}

Bardin, L. (1977). L`analyse of contenu. Paris: PUF.

Caldeira, G. (2001). Os aspectos psicológicos da dor. In G. Caldeira \& J. D. Martins (Org.). Psicossomática: Teoria e prática (pp. 21). Rio de Janeiro: Medsi.

Caprara, A., \& Rodrigues, J. (2004). A relação assimétrica médico-paciente: Repensando o vínculo terapêutico. Ciência \& Saúde Coletiva, 9(1), 139-146.

Craig, C. (2005). Pilates com a bola. São Paulo: Phorte.

Copetti, F. (2001). Estudos exploratórios dos atributos pessoais de tenistas. Tese de Doutorado em ciência do Movimento Humano, Universidade Federal de Santa Maria, Santa Maria.

Ferreira, J. (1993). 0 corpo sígnico: Representações sociais sobre corpo, sintomas e sinais em uma vila de classes populares. Dissertação de Mestrado em Psicologia, Universidade Federal do Rio Grande do Sul, Porto Alegre, 1993.

Gadamer, H. G. (1994). Dove si Nasconde la salute. Milano: Raffaelo Cortina.

Garcia, A. (Org.). (2005). Relacionamento interpessoal: Olhares diversos. Vitória: UFES. 
Kolyniak, I. E. G., Cavalcanti, S. M. B., \& Aoki, M. S. (2004). Avaliação isocinética da musculatura envolvida na flexão e extensão do tronco; efeito do método Pilates. Revista Brasileira Medicina do Esporte, 10(6), 487-490.

Lobato, O. (1992). 0 problema da dor. In J. F. Mello (Org.). Psicossomática hoje (pp. 165-178). Porto Alegre: Artes Médicas.

Loyola, M. A. (1984). Médicos e curandeiros: Conflito social e saúde. São Paulo: Difel.

Marinho, P. E. M. (1995). Escutar: Aspecto relevante da relação fisioterapeuta-paciente na fisioterapia. Fisioterapia em Movimento, 7(2), 59-62.

Marinho, P. E. M. (2005). Refletindo sobre a expressividade da dor e a relação terapeuta-paciente. Fisioterapia em Movimento, 18(2), 73-79.

Marinho, A. P., \& Fiorelli, J. O. (2005). Psicologia na fisioterapia. São Paulo: Atheneu.

Moreira, V., Nogueira, F. N. N., \& Rocha, M. A. S. (2007). Leitura fenomenológica do adoecer em pacientes do serviço de Fisioterapia do Núcleo de Atenção Médica Integrada, Universidade de Fortaleza. Estudos de Psicologia, 24(2), 191-203. doi: 10.1590/S0 103-16672007000200006
Patton, M. Q. (1980). Qualitative evaluation methods. Beverly Hills, CA: Sage.

Perestrello, D. (1989). A medicina da pessoa. Rio de Janeiro: Atheneu.

Pilates, J. H., \& Miller, W. J. (1998). A Pilates Primer: The mullenium edition - Return to life through contrology and your health. New York: Presentation Dynamics.

Ribeiro, J., Moraes, M. V. M., \& Beltrame, T. S. (2008). Tipo de atividade interpessoal estabelecida entre fisioterapeuta e criança com paralisia cerebral no contexto de intervenção Fisioterapêutica. Dynamis: Revista Técnico Científica, 14(1), 89-95.

Selby, A., \& Herdman, A. (2000). Pilates: Como criar o corpo que você deseja. São Paulo: Manole.

Silva, M. J. P. (1996). Comunicação tem remédio: A comunicação nas relações interpessoais em saúde (2a ed.). São Paulo: Gente.

Ungaro, A. (2002). Pilates body in motion. New York: Dorling Kindersley Book.

Wulff, H. R., Pedersen, S. A., \& Rosemberg, R. (1995). La filosofia della Medicina. Milano: Raffaelo Cortina. 